\title{
EDITORIAL
}

\section{Nutrition, growth, and development}

What is known about relationships between nutrition, growth, and development is well summarized in three recent reports of meetings held to discuss these problems: the Proceedings of the International Conference held at Massachusetts Institute of Technology in 1967 and edited by Scrimshaw and Gordon (1968); the little publicized Pan American Health Organization Seminar held at the University of the West Indies, Jamaica, in 1972; and the 1973 Swedish Symposium on early malnutrition and mental development edited by Cravioto, Hambraeus, and Vahlquist, and the papers given at the ensuing W.H.O. Workshop on methodological problems in studies of early malnutrition and mental development-both published by the Swedish Nutrition Foundation (1974). It cannot be said that very much is firmly established concerning specific effects of poor nutrition on human performance: malnutrition is part of the 'cycle of poverty' and its effects in humans cannot be separated from other aspects of this 'cycle'. Much of our knowledge, therefore, comes from animal studies the applicability of whose findings to man is often questionable.

\section{NUTRITION AND SOMATIC GROWTH}

The growth of biological organisms depends upon their nutrition. Improvements in nutrition are responsible for the secular changes in adult human stature which, in the case of European males, has increased by $2.5 \mathrm{~cm}$ per generation ( 25 years) during the last century or more (Khosla and Lowe, 1968). There is also evidence (Massachusetts Institute of Technology, 1968, pp. 16-91; Habicht et al., 1974) that in well-fed populations racial differences in growth during early childhood are small (means varying by not more than $3 \%$ for height and $6 \%$ for weight). In developing countries, however, social class differences in mean height amount to $12 \%$ and in mean weight to $30 \%$; children in the best-fed sections of the population approach well-fed European and North American children in their growth achievements, while those in the poor sections of the population lag very seriously behind.

These findings apply to children who are chronically undernourished. A number of investigators, following McCance's early work, have also looked at the effects on subsequent growth of acute episodes of nutritional deprivation. The timing, severity, and duration of the nutritional insult all contribute to the long-term effects. Dobbing (1968) has formulated a general principle which encompasses the findings; it states that, if a developmental process is restricted by any agency at the time of its fastest rate, not only will this delay the process but it will restrict the ultimate extent, even when the restricting influence is removed and the fullest possible rehabilitation obtained. He adds two corollaries. First, the severity of the restriction required to produce a given ultimate deficit is less the nearer it is applied to the time of fastest growth; the same effect may be achievable later in development, but only by a much greater restriction over a much longer period of time. Secondly, such effects are not achievable in the adult.

These principles are of general applicability as far as is known. In all mammals 'catch-up' at later periods in life depends upon the timing, duration, and intensity of the nutritional insult.

\section{BRAIN GROWTH}

Dobbing and his colleagues have summarized our knowledge of this; elegant presentations are given in all three of the reports mentioned above (see also Dobbing anu Smart, 1974). The evidence supports the view that the basic stages of brain jevelopment are virtually identical in all animals. A 
period of embryological growth is followed by one of predominantly neuronal cell division so that the adult number of neurones is almost completely achieved quite early. This stage is followed by an exceedingly rapid phase of oligodendroglial multiplication. During this period myelin is formed, dendritic growth and branching occur, synaptic connections are formed, and profound neurochemical changes take place.

In humans the first of these stages (that of neuronal multiplication) occurs during the second trimester of pregnancy and the second (often referred to as the 'brain growth spurt') follows on, during the last trimester of intrauterine life and the first 18 to 24 months of postnatal life. It seems unlikely that maternal malnutrition severe enough to influence neuronal cell proliferation is compatible with survival of the fetus; this is not the case during the brain growth spurt, however. Throughout the developing world nutritional privation leading to diminished brain size and head size is very common.

Studies of rats in standard laboratory conditions show that food deprivation at 'critical' stages causes distortion in brain growth and irreversible changes in cell composition (Dobbing, 1968), as well as reductions in brain weight and cell number.

\section{PERFORMANCE}

Less work has been done on the learning abilities and 'performance' of animals differently fed but subject to a common environment. The literature is not altogether consistent, some investigators reporting elevations in response rates, some a lowering of responsiveness in chronically undernourished animals. Differences in the experimental set-ups are probably responsible for these inconsistencies. There is evidence from a number of studies that rats malnourished during the brain growth spurt are both more apathetic and more irritable or 'emotional' than are standard laboratory animals. In optimal conditions there may be no differences in learning and performance, but behaviour is adversely affected by slight changes in the environment which do not effect rats which have been normally fed. Dobbing and Smart (1974) report that rats malnourished during the sensitive growth spurt period are more clumsy than control animals. This is presumably because of cerebellar dysfunction-the cerebellum grows particularly rapidly during that period.

Human studies show that chronically ill-fed children also perform more poorly on psychological tests than well-fed ones. Birch and Gussow (1970) offer the most comprehensive review of this literature. Likewise, children who have been hospitalized for severe clinical malnutrition during early childhood also perform badly on tests on average. However, the interpretation of human findings is made difficult by the fact that malnourished children commonly live in a psychologically adverse environment. Mönckeberg (1968) and Klein et al. (1974) report that better feeding of ill-nourished children in Colombia and Guatemala did not result in better school performance or IQ changes; on the other hand, Richardson (1972) in Jamaica (Tizard, 1974), and Cravioto and Delicardie (1972) in Mexico have reported that the intellectual development of children clinically malnourished in infancy is affected both by their biological and by their social environment. Christiansen et al. (1974) have also argued, on the basis of findings from an ongoing study in Bogota, Colombia, that 'although (chronic) malnutrition and social environment are closely associated, a strong relationship exists between malnutrition and intellectual function in young children even when effects of social and health factors are controlled'. In Richardson's (1972) report on a study of 71 boys hospitalized in Jamaica who were followed-up several years later and compared with boys of the same age and at the same class of school, it was shown that relations between home stimulation, clinical malnutrition in infancy, and IQ could be accounted for by an additive model. In this study each condition was associated with a mean loss of 10 points of IQ, so that children who were both malnourished in infancy and who lived in unstimulating homes, had IQs which on average were 20 points lower than those of comparison children who had not been malnourished and who lived in more stimulating homes. The intellectual development of malnourished children living in more stimulating home circumstances, and that of children who were not malnourished but who lived in poor environments, were about equal, and were half way between those of the other two groups. 


\section{INTERGENERATIONAL EFFECTS}

Studies with animals malnourished for several generations show that they fail to attain the same size as control rats (Stewart, 1973). When young, they have an enhanced exploratory behaviour, react violently to noise, and are slower and less likely to solve visual discrimination tests than are normal rats. There are remarkable differences in the growth of animals rehabilitated at different stages of development (Stewart, 1974, and personal communication). Surprisingly, malnourished mothers well fed from the 14th day of pregnancy produce offspring which grow significantly larger than normal. However, such animals still exhibit the enhanced exploratory behaviour and excessive reaction to noise. Their performance in visual discrimination tests is much nearer that of the controls than that of the non-rehabilitated rats. The behavioural changes may persist, mimicking genetic effects, but after two or three generations the effects 'wash out' and subsequent generations become normal in growth and behaviour.

Cravioto et al. (1966) and Birch and Gussow (1970) have drawn attention to intergenerational influences likely to affect human development. Malnourished children are born to mothers who were themselves malnourished. They are on average of small size at birth, more subject to sickness and ill health, less adequately cared for in childhood, and commonly brought up in an intellectually stultifying environment. They do badly in school. But it is not possible to say to what extent subnutrition is a direct cause of their school failure (through its effects upon growth of brain structure); or an indirect cause (in inducing apathy, increasing sickness which will result in absenteeism, or affect motivation and aspiration); or a contributory cause in the 'cycle of poverty'.

\section{ENVIRONMENTAL INFLUENCES}

Environmental factors can be shown to produce effects similar to those of nutritional deprivation. Moreover, environmental stimulation can offset many of the ill-effects of malnutrition.

Fran̆ková (1974) summarizes 33 studies of early physical stimulation in rats leading to acceleration of growth, precosity in development of motor and sensory functions, increased brain weight, more rapid myelination, accelerated development of an adult EEG, earlier maturation of the hypothalmopituitary system, increased exploratory activity in childhood, lower emotionality and less emotional response to stress situations, better adaptation to different pathogenic agents, better survival from starvation, smaller gastrointestinal lesions in conflict situations, and differences in sensitivity to certain stimuli. The effects depend upon the timing of the stimulation or handling given to the young rats. Frañková herself is also undertaking an imaginative and signifičnt series of studies on the effects of a more stimulating social environment in improving the performance and behaviour of rats ill nourished during infancy. The experimental design, in which a control group is also used, is to keep one group of the protein-deprived rats not only with their mother, but also with an 'aunt', a non-pregnant virgin female rat which has previously been acquainted with small rats fed on the basal diet. The 'aunt' is present during the day but is not fed there. So far Frañková has studied the effect of the increased social stimulation on the behavioural patterns of the infant rats on days 21 and 28. Whereas protein-calorie deprived infant rats reared with their mothers alone exhibited a low level of spontaneous exploratory activity and a small number of social contacts, together with behaviour such as freezing, trembling, and stereotyped head movements, the behaviour of the malnourished rats raised with their 'aunt' differed markedly:

'All kinds of exploratory activity were enhanced, and they had significantly more contact with their littermates as well as with their mother. Symptoms of abnormal behaviour declined. In behavioural tests they did not differ from the control rats that were raised without an "aunt". It was interesting that not only the behaviour of the infants but also that of the mother was influenced by the three weeks presence of the "aunt" in the breeding cage. The number of active contacts with the offspring increased as a result of "aunt's" presence with the protein-deprived family'.

Frañková's researches are still at an early stage, but already they illustrate the importance, in animal studies of development and performance, of paying attention to the definition and systematic 
experimental study of specific aspects of the environment. Just as Harlow's work on the behavioural development and learning capacities of monkeys became richer and more informative when he began studies in which he systematically explored the stimulus properties of social and material features of the environment, including those which constitute different patterns of rearing, so Frañková's work points to ways in which the contradictions in the existing findings concerning the behaviour of malnourished animals may possibly be reconciled and knowledge extended once attention is paid to environmental variables. As Hebb (1949) pointed out, animals reared in standard laboratory cages live in an environment so unstimulating that genetically determined adaptive potentialities may remain undeveloped and unrealizable. In consequence when they are tested on tasks which require adaptive or cognitive skills for their successful performance both means and variances are reduced: the animals have not experienced the necessary environmental conditions which would enable them to express differences in potential or capacity. A major problem in developmental psychology is therefore to define the stimuli, conditions and experiences which are 'adequate' for the expression of behaviours. A significant feature of contemporary work on brain growth is that it shows that by adjusting the timing of dietary and other 'physical' types of intervention to take account of ageappropriate, species-specific stages of growth it becomes possible to make inter-species generalizations. So also it may be possible through the manipulation of age-appropriate, species-specific environmental conditions to make inter-species generalizations about the development of behaviour.

Another new line of inquiry, also reported at the Swedish Symposium, has been opened up by Chávez and his colleagues (1974) in Mexico. These workers were interested in the growth of children, and in patterns of family interaction, after food supplementation. Twenty pregnant women from an undernourished village population were given food supplementation from the sixth week of pregnancy through the next three years. Their offspring were also given adequate nutrition, supplementary feeding being introduced at three months and continued in a suitable form during infancy and early childhood. Chávez reports marked differences not only in the growth of the supplemented children as compared with controls, but also in their behaviour. By eight months the supplemented children were out of their cots practically the entire day while the non-supplemented children remained in their cots between 10 and $20 \%$ of the time. They were quicker to walk and spent less time being carried. They went out of doors more often, slept less, talked more, and cried less. They themselves were much more active in taking the initiative with their mothers. Both mothers and fathers were more active with their children, were reported to take more pride in them, and provided a more stimulating environment for them. A striking feature of Chávez's report is that he stresses the manner in which the children themselves acted as agents of change. The supplemented children took the initiative in structuring their environment, increasing the frequency and the variety of their contacts with adults and in general creating conditions which facilitated mental growth.

Chávez's work, like other, recent research in human development from birth onwards stresses the active role of the child in providing the conditions required for his own development. This way of thinking about development takes us beyond the rather static concepts of 'stages' passing before our eyes like floats in a carnival depicting the stages of history. And though we are a long way from adequate sociobiological models to account for interactive processes in development, it seems more likely that a science of child development will emerge from the study of such processes rather than from the reification of mental structures or 'dimensions' of personality.

\section{IMPLICATIONS}

To readers of this journal Fran̆ková's work and that of Chávez and his colleagues are likely to be among the most interesting of the recent reports of ongoing work in nutrition. It seems likely that Stewart's work, when published, will also contribute very substantially to our knowledge of the mechanisms, and of the timing, of growth and its relation to function. (One can, indeed, only regret that Stewart's work is due to stop shortly-just at a time, it may seem, when it is opening whole new areas of study.) All the signs are that during the next few years there will be substantial advances in our knowledge of factors affecting growth and learning. There is, unfortunately, less reason to be 
sanguine about advances concerned with the biological basis of temperament and conation. We still lack discriminating indicators of affective and motivational behaviour.

Finally, though current research in nutrition is of scientific interest and importance, one cannot help wondering what contribution it is all making to the human problems of chronic undernutrition and to the mobilization of the human resources required to meet it. Malnutrition is, as Vahlquist remarked in his closing address to the Swedish Conference, only one segment of the culture of poverty. Nonetheless it is a crucial segment. It is to be hoped, therefore, that at the next international conference on malnutrition economists, demographers, food technologists, political scientists, sociologists, and educators will play a major part. For the study of nutrition is above all a human and political question, and the scientific questions which relate to biology and psychology make up only a small part of the whole.

JACK TIZARD

\section{REFERENCES}

Birch, H. G., and Gussow, J. D. (1970). Disadvantaged Children: Health, Nutrition and School Failure. Grune and Stratton: New York.

Chávez, A., Martínez, C., and Yaschine, T. (1974). The importance of nutrition and stimuli on child mental and social development. In Early Malnutrition and Mental Development, pp. 211-225. Edited by J. Cravioto, L. Hambraeus, and B. Vahlquist. Symposia of the Swedish Nutrition Foundation 12. Almqvist and Wiksell: Stockholm.

Christiansen, N., Vuori, L., Mora, J. O., and Wagner, $\mathbf{M}$. (1974). Social environment as it relates to malnutrition and mental development. In Early Malnutrition and Mental Development, pp. 186-201. Edited by J. Cravioto, L. Hambraeus, and B. Vahlquist. Symposia of the Swedish Nutrition Foundation 12. Almqvist and Wiksell: Stockholm.

Cravioto, J., and DeLicardie, E. R. (1972). Environmental correlates of severe clinical malnutrition and language development in survivors from kwashiorkor or marasmus. In Nutrition, the Nervous System, and Behavior, pp. 73-94. Scientific Publication No. 251. Pan American Health Organization: Washington.

Cravioto, J., DeLicardie, E. R., and Birch, H. G. (1966). Nutrition, growth and neurointegrative development: an experimental and ecologic study. Pediatrics, 38, 319-373.

Dobbing, J. (1968). Vulnerable periods in developing brain. In Applied Neurochemistry, pp. 287-316. Edited by A. N. Davison and J. Dobbing. Blackwell: Oxford.

Dobbing, J., and Smart, J. L. (1974). Vulnerability of developing brain and behaviour. British Medical Bulletin, 30, 164-168.

Frañková, A. (1974). Interaction between early malnutrition and stimulation in animals. In Early Malnutrition and Mental Development, pp. 202-210. Edited by J. Cravioto, L. Hambraeus, and B. Vahlquist. Symposia of the Swedish Nutrition Foundation 12. Almqvist and Wiksell: Stockholm.

Habicht, J.-P., Martorell, R., Yarbrough, C., Malina, R. M., and Klein, R. E. (1974). Height and weight standards for preschool children. Lancet, 1, 611-615.

Hebb, D. O. (1949). The Organization of Behavior. Wiley: New York.
Khosla, T., and Lowe, C. R. (1968). Height and weight of British men. Lancet, 1, 742-745.

Klein, R. E., Yarbrough, C., Lasky, R. E., and Habicht, J.-P. (1974). Correlations of mild to moderate proteincalorie malnutrition among rural Guatemalan infants and preschool children. In Early Malnutrition and Mental Development, pp. 168-181. Edited by J. Cravioto, L. Hambraeus, and B. Vahlquist. Symposia of the Swedish Nutrition Foundation 12. Almqvist and Wiksell: Stockholm.

Massachusetts Institute of Technology, Cambridge, Mass. (1968). Malnutrition, Learning and Behavior. Proceedings of an International Conference cosponsored by The Nutrition Foundation, Inc., and the Massachusetts Institute of Technology held at Cambridge, Mass., 1967. Edited by N. S. Scrimshaw and J. E. Gordon. M.I.T. Press: Cambridge, Mass.

Mönckeberg, F. (1968) Effect of early marasmic malnutrition on subsequent physical and psychological development. In Malnutrition, Learning and Behavior, pp. 269-278. Edited by N. S. Scrimshaw and J. E. Gordon. M.I.T. Press: Cambridge, Mass.

Pan American Health Organization (1972). Nutrition, the Nervous System, and Behavior. Proceedings of the Seminar on Malnutrition in Early Life and Subsequent Mental Development, Mona, Jamaica, 1972. Scientific Publication No. 251. Pan American Health Organization: Washington.

Richardson, S. A. (1972). Ecology of malnutrition: nonnutritional factors influencing intellectual and behavioral development. In Nutrition, the Nervous System, and Behavior, pp. 101-110. Scientific Publication No. 251. Pan American Health Organization: Washington.

Stewart, R. J. C. (1973) A marginally malnourished rat colony. Nutrition Reports International, 7, 487-493.

Stewart, R. J. C. (1974). Experimental studies on nutrition and brain development. Nutrition, 28, 151-162.

Swedish Nutrition Foundation (1974). Early Malnutrition and Mental Development. Symposia of the Swedish Nutrition Foundation 12. Edited by J. Cravioto, L. Hambraeus, and B. Vahlquist. Almqvist and Wiksell: Stockholm.

Tizard, J. (1974). Early malnutrition, growth and mental development in man. British Medical Bulletin, 30, 169-174. 